Supporting Information for:

\title{
Phenanthriplatin Acts as a Covalent Poison of Topoisomerase II Cleavage Complexes
}

\author{
Imogen A. Riddell, ${ }^{\mathrm{a}}$ Keli Agama, ${ }^{\mathrm{b}}$ Ga Young Park, ${ }^{\mathrm{a}}$ Yves Pommier, ${ }^{\mathrm{b}, \dagger}$ and \\ Stephen J. Lippard ${ }^{\mathrm{a}, \dagger}$ \\ a Department of Chemistry, Massachusetts Institute of Technology, Cambridge, \\ MA 02139 \\ ${ }^{\mathrm{b}}$ Center for Cancer Research, National Cancer Institute, Bethesda, MD 20892
}

\section{Table of Contents}

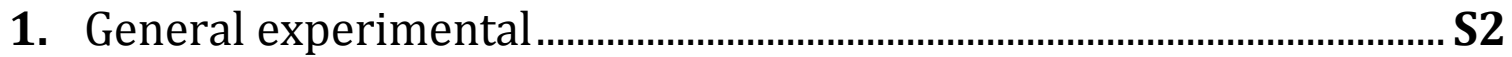

2. Detection of Top2cc by immunoblotting/in-vivo complex of enzyme (ICE) bioassay

3. Alkaline elution assays to detect DNA Protein Complexes...................... S2

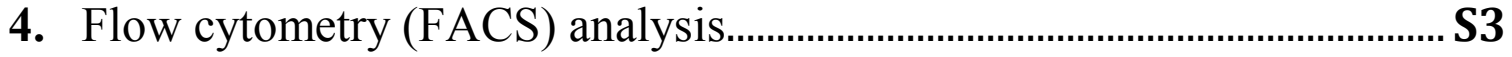

5. Topoisomerase II-mediated DNA cleavage reactions..................................S4

6. Determination of Platinum binding site on 117-bp Oligonucleotide ...... S7

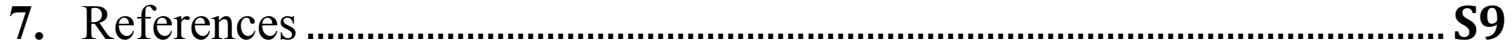




\section{General experimental}

Purified, recombinant human Top $2 \alpha$ and Top $2 \alpha$ monoclonal antibodies were provided by Dr. John Nitiss (St. Jude Children's Research Hospital, Memphis, TN). Phenanthriplatin was synthesized as previously reported. ${ }^{l}$ Oligonucleotides were purchased from Integrated DNA Technologies (Coralville, Iowa). Etoposide was purchased from SigmaAldrich. DNAzol was purchased from Invitrogen. Radioisotopes including $\left[{ }^{14} \mathrm{C}\right]$ thymidine, $\left[\gamma^{32} \mathrm{P}\right]$-dGTP and $\left[\gamma-{ }^{32} \mathrm{P}\right]$-ATP were purchased from Perkin-Elmer Life Science Co., Boston, MA. T4 PNK and Taq DNA polymerase were supplied from New England Biolabs. Individual dideoxy nucleotides and deoxynucleotide mix were supplied by Affymatix. Gels were dried using a Labconco gel drier and visualized using a Phosphoimager from Molecular Dynamics (Sunnyvale, CA) and ImageQuant software, or a Storm 840 Phophorimager system from Amersham Biosciences with data analysis performed using Quantity One Software (Bio-Rad).

\section{Detection of Top2cc by immunoblotting/in-vivo complex of enzyme (ICE) bioassay}

HT-29 cells $\left(2.5 \times 10^{6}\right)$ were exposed to etoposide for $3 \mathrm{~h}$ or phenanthriplatin for $1,2,3$ or $5 \mathrm{~h}$. After drug treatment, cells were lysed in DNAzol., and genomic DNA was purified according to the manufacturer's instructions. Samples were sonicated briefly to shear the DNA, then varying concentrations of DNA were spotted on transfer membranes (Immobilon-FL; Millipore) using a slot-blot manifold (GE Healthcare). Covalent Top2DNA complexes were detected by immunoblotting using Top $2 \alpha$ monoclonal antibody. The experiment was performed in duplicate.

\section{Alkaline elution assays to detect DNA Protein Complexes}

Alkaline elution was used to quantitate DNA-protein crosslinks (DPC) as described in

detail previously. ${ }^{2}$ Briefly, cellular DNA was radiolabeled with $\left[{ }^{14} \mathrm{C}\right]$ thymidine for $24 \mathrm{~h}$ at $37{ }^{\circ} \mathrm{C}$ and chased in non-radioactive medium for at least $4 \mathrm{~h}$. After drug treatments, 
cells were counted to determine the appropriate loading. Aliquots were placed in drugcontaining ice-cold HBSS. After alkaline elution, filters were incubated at $65{ }^{\circ} \mathrm{C}$ with 1 $\mathrm{M} \mathrm{HCl}$ for $45 \mathrm{~min}$ and $0.04 \mathrm{M} \mathrm{NaCl}$ was added for an additional $45 \mathrm{~min}$. Radioactivity in all fractions was measured with a liquid scintillation analyzer (Packard Instruments, Meriden, CT). DPC were analyzed under non-deproteinizing, DNA-denaturing conditions ( $\mathrm{pH}$ 12.1) using protein-adsorbing filters.

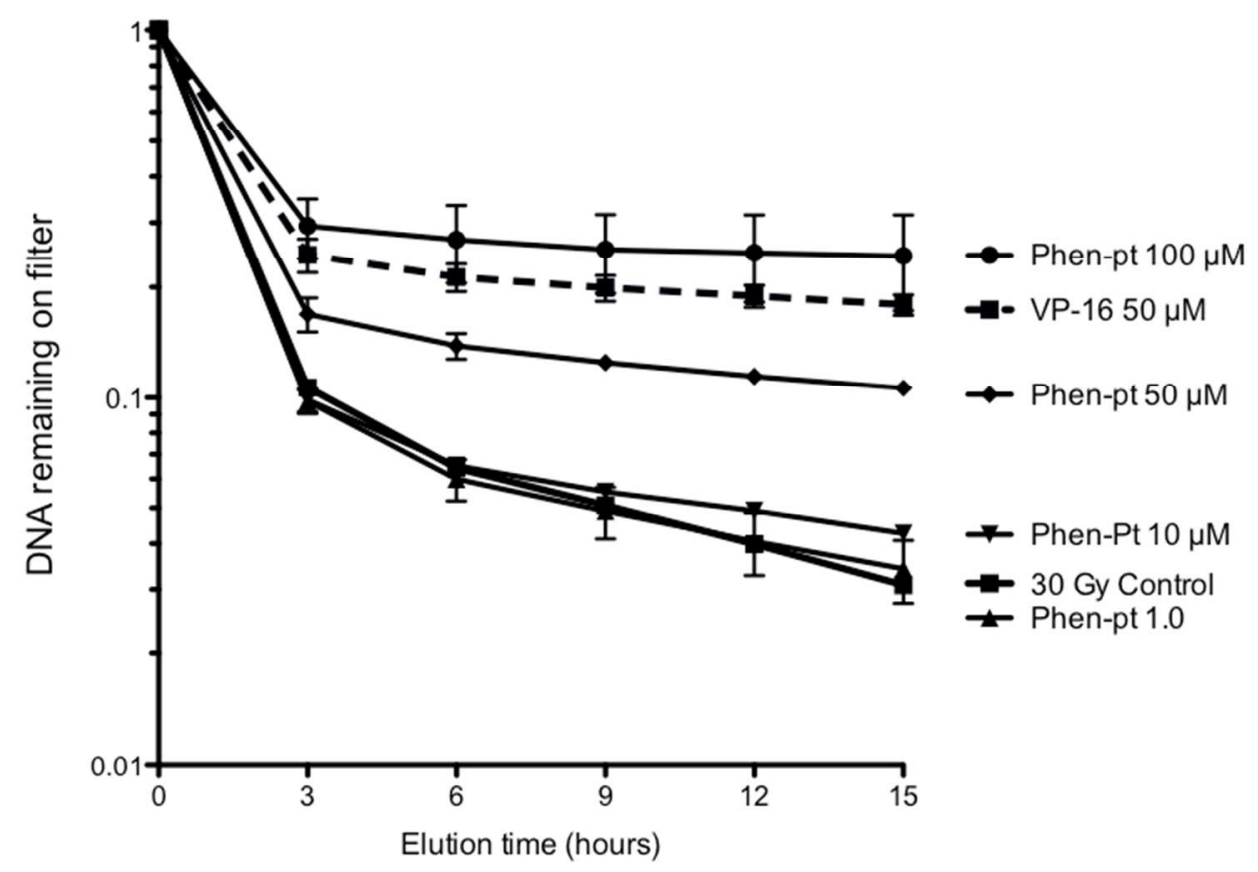

Figure S1: Representative alkaline elution experiment showing total DPC in cells exposed to $1,10,50$ and $100 \mu \mathrm{M}$ phenanthriplatin. Alkaline elution results are expressed in rad-equivalents as previously described. ${ }^{2}$ Data at each concentration of phenanthriplatin represent three independent determinations.

\section{Flow cytometry (FACS) analysis}

For cell cycle analysis, cells were prepared and analyzed with a LSRII Fortessa flow cytometer (BD Biosciences) using the FACSDiva software (BD Biosciences). 


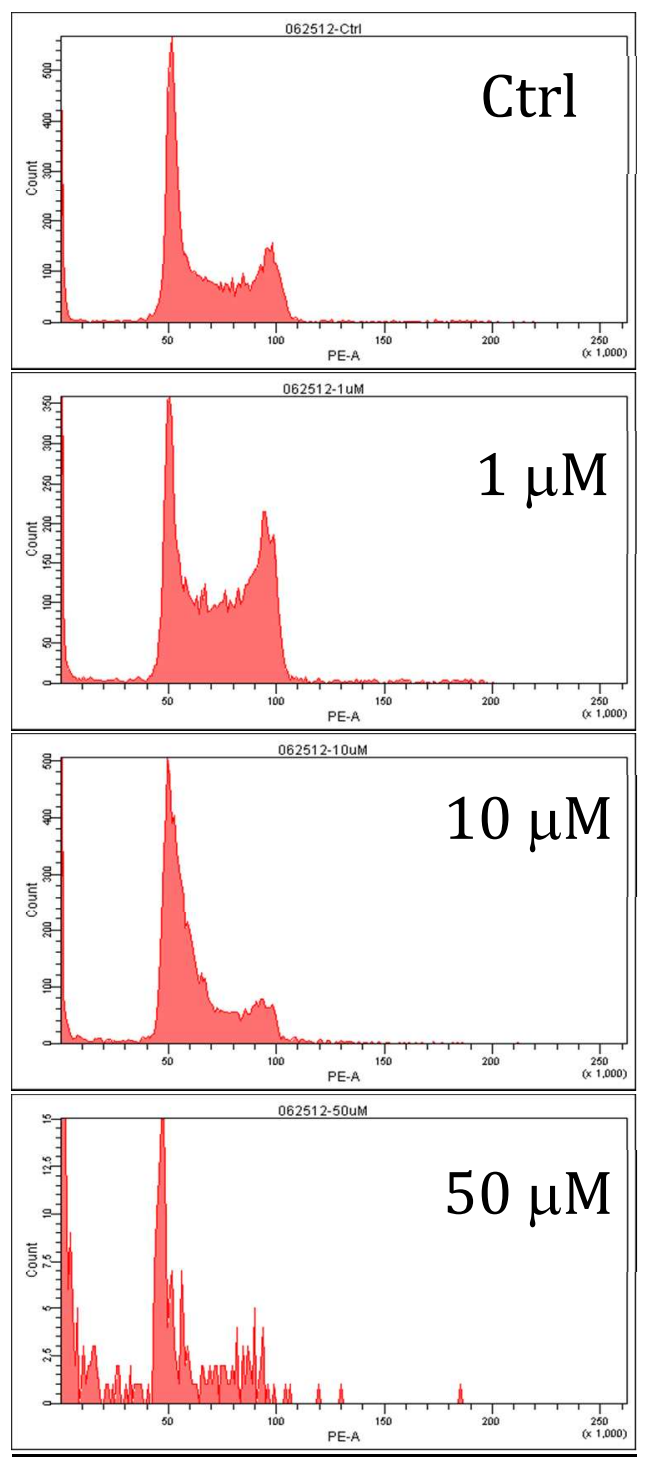

Figure S2: FACS analysis showing cell cycle arrest and cell death (sub-G1 cells) in HT29 colon carcinoma cells treated with 1,10 or $50 \mu \mathrm{M}$ phenanthriplatin for $15 \mathrm{~h}$.

\section{Topoisomerase II-mediated DNA cleavage reactions}

A 117-bp DNA oligonucleotide encompassing the previously identified Top2 cleavage sites identified in the 161-bp fragment from pBluescript SK(-) phagemid DNA was employed. This 117-bp DNA oligonucleotide was $5^{\prime}$-end labeled using PNK and $\left[\gamma_{-}{ }^{32} \mathrm{P}\right]$ ATP in PNK buffer (70 mM Tris-HCl, $10 \mathrm{mM} \mathrm{MgCl}_{2}, 5 \mathrm{mM}$ DTT, $\cdot \mathrm{pH}$ 7.6). Unincorporated $\left[{ }^{32} \mathrm{P}\right]$-dGTP was removed using mini Quick Spin DNA columns (Roche, 
Indianapolis, IN), and the eluate containing the $5^{\prime}$-end-labeled DNA substrate was collected. Approximately $4.5 \mathrm{nM}$ of radiolabeled DNA substrate was pre-incubated with various concentrations of phenanthriplatin for three to five $\mathrm{h}$ at $37{ }^{\circ} \mathrm{C}$ and then added to recombinant Top2 in $10 \mu \mathrm{L}$ of reaction buffer $(10 \mathrm{mmol} / \mathrm{L}$ Tris- $\mathrm{HCl}(\mathrm{pH} 7.5), 50 \mathrm{mM}$ $\mathrm{KCl}, 5 \mathrm{mM} \mathrm{MgCl} 2,1 \mathrm{mM}$ ATP, $0.2 \mathrm{mM}$ DTT, $0.1 \mathrm{mM}$ EDTA, and $15 \mu \mathrm{g} / \mathrm{mL} \mathrm{BSA}$ ) at 25 ${ }^{\circ} \mathrm{C}$ for $30 \mathrm{~min}$. The reactions were terminated by adding SDS ( $0.5 \%$ final concentration) followed by the addition of two volumes of loading dye $(80 \%$ formamide, $10 \mathrm{mM}$ sodium hydroxide, $1 \mathrm{mM}$ sodium EDTA, $0.1 \%$ xylene cyanol, and $0.1 \%$ bromophenol blue). Aliquots of each reaction were subjected to $20 \%$ denaturing PAGE.

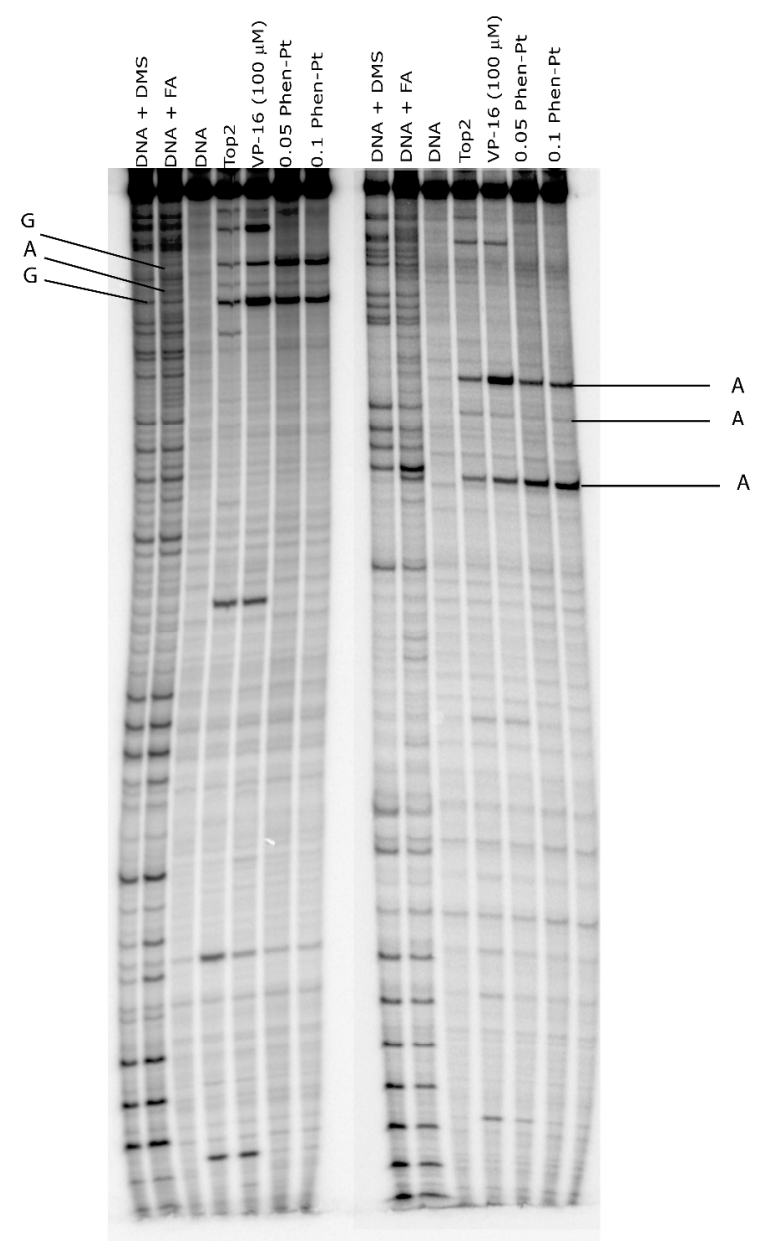

Figure S3: DNA Cleavage assay employing Maxam-Gilbert sequencing of the fulllength 117-bp pSK sequence; left-hand side forward strand, right-hand side reverse strand. Dimethyl sulfate (DMS) sequencing was used to map guanine positions. Formic acid (FA) was used to map either guanine or adenine. 


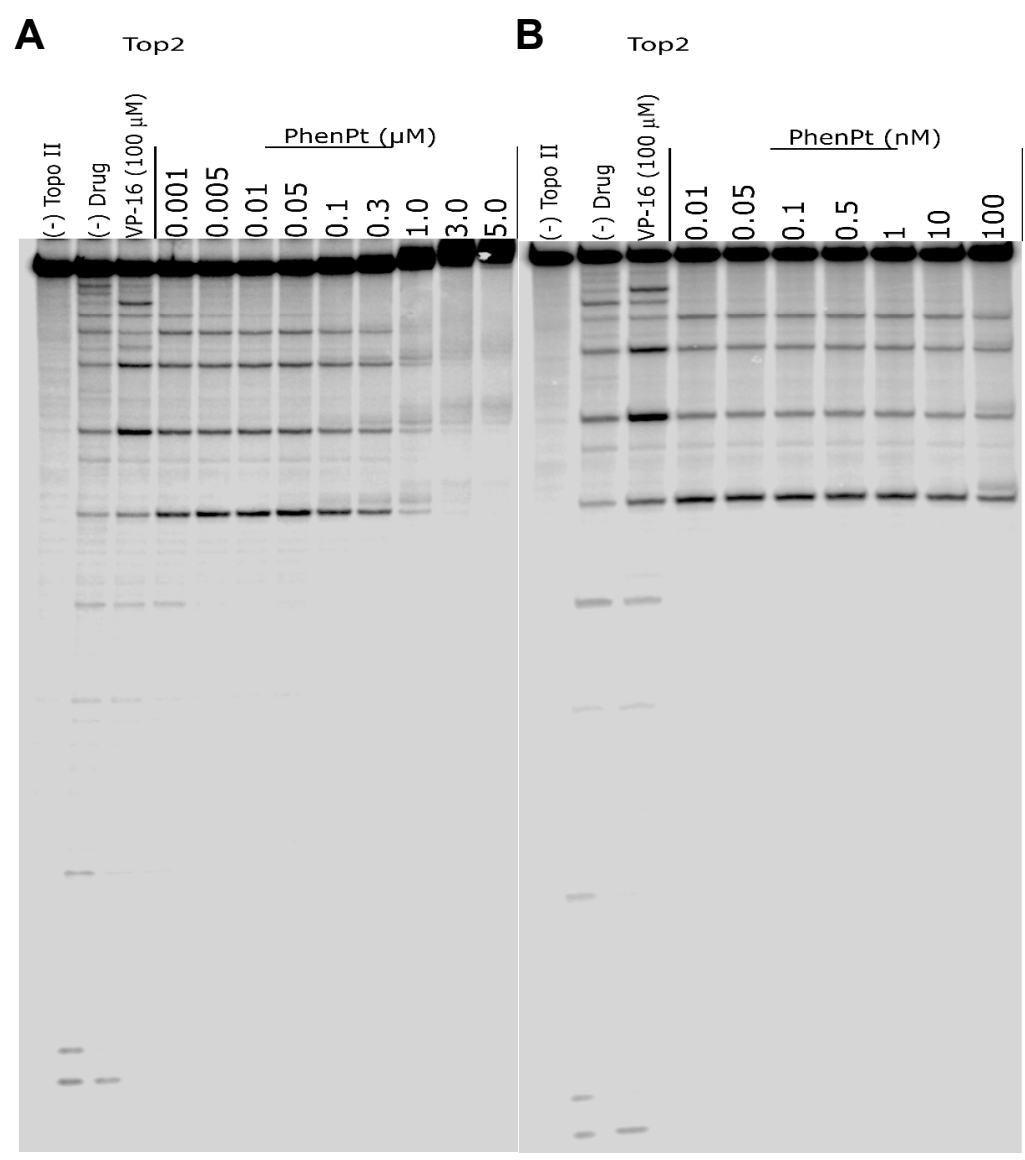

Figure S4: Phenanthriplatin traps Top2cc in-vitro at micromolar $\mathbf{A}$, and nanomolar concentrations B. A: (lane 1) DNA alone; (lane 2) Top2 alone; (lane 3) VP-16 (etoposide); (lanes 4-12) Top2 + phenanthriplatin (Phen-Pt) at the indicated micromolar concentrations. B: (lane 1) DNA alone; (lane 2) Top2 alone; (lane 3) VP-16 (etoposide); (lanes 4-12) Top2 + phenanthriplatin (Phen-Pt) at the indicated nanomolar concentrations. The DNA corresponds to a 5'-end-labeled 117-bp DNA oligonucleotide from the 161-bp fragment from pBluescript SK(-) phagemid DNA. For the cleavage assay reactions, labeled DNA was incubated with phenanthriplatin (Phen-Pt) at the indicated concentrations for $2-3 \mathrm{~h}$ at $37{ }^{\circ} \mathrm{C}$ before adding the reaction mix and Top 2 for $30 \mathrm{~min}$ at $21^{\circ} \mathrm{C}$. DNA was reacted alone (-Top2), with Top2 in the absence of drug (drug) or in the presence of the indicated concentrations $(\mu \mathrm{mol} / \mathrm{L})$ of VP-16 or phen-pt. Reactions were stopped by adding 0.5\% SDS. DNA fragments were separated in 20\% denaturing polyacrylamide gels. 


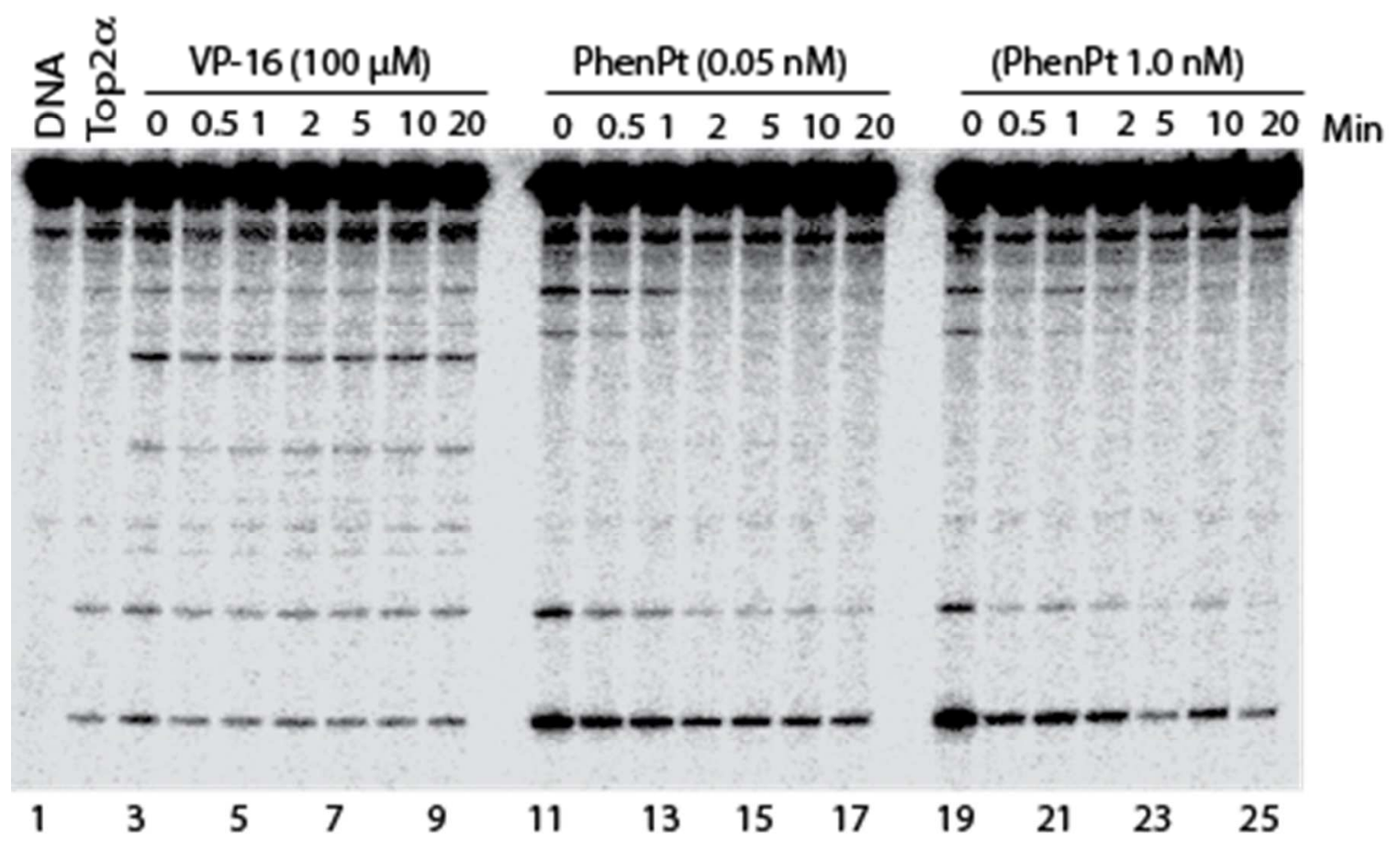

Figure S5: Reversibility of the Top2ccs induced by phenanthriplatin. After 20 min of incubation with $100 \mu \mathrm{M}$ of VP-16 (etoposide) or 0.05 or $1.0 \mathrm{nM}$ phenanthriplatin, $0.35 \mathrm{M} \mathrm{NaCl}$ was added to induce the reversal of the Top2ccs. Aliquots were taken and reactions were terminated at the indicated time points with $0.5 \%$ SDS: 0 , immediately before $\mathrm{NaCl}$ addition (lanes 3,11 and 19), 0.5 min (lanes 4, 12 and 20), 1 min (lanes 5, 13 and 21), 2 min (lanes 6, 14 and 22), 5 min (lanes 7, 15 and 23), 10 min (lanes 8, 16 and 24) and 20 min (lanes 9, 17 and 25). Reaction buffers, labeled DNA and recombinant Top2 2 were all as described in the Top2cc procedure.

\section{Determination of Platinum binding site on 117-bp Oligonucleotide}

\subsection{Platination of 118 bp Oligonucleotide:}

Purified 117-bp DNA (5 pmol, $100 \mathrm{nM}$ ) was incubated with either phenanthriplatin or cisplatin $\left(r_{f}\right.$ (platinum to nucleotide) $\left.=0.012,0.025,0.05,0.1\right)$ in $1 \mathrm{mM}$ sodium phosphate, $\mathrm{pH} 7.4,3 \mathrm{mM} \mathrm{NaCl}$ solution at $37^{\circ} \mathrm{C}$ for $3 \mathrm{~h}$. Following reaction the samples underwent ethanol precipitated upon addition of $\mathrm{NaOAc}(5 \mu \mathrm{L}, 3 \mathrm{M})$ and $155 \mu \mathrm{L}$ ice cold ethanol, and incubation at $-80{ }^{\circ} \mathrm{C}$ for $2 \mathrm{~h}$. Following precipitation samples were centrifuged at $4{ }^{\circ} \mathrm{C}, 13000 \mathrm{rpm}$ for 30 minutes, the supernatant was decanted and the 
pellet was washed twice with ice-cold ethanol. After isolation the samples were stored at $-20{ }^{\circ} \mathrm{C}$.

\subsection{Linear Amplification:}

One pmol of primer (Primer 1: 5'-GCGAT TAAGT TGGGT AACG (19mer), Primer 2: 5'- GACCT CGAGG GGGGG CCGGT AC (22mer)) was 5'-labeled in a final volume of $20 \mu \mathrm{L}$ with $70 \mathrm{mM}$ Tris- $\mathrm{HCl}, \mathrm{pH} 7.4,10 \mathrm{mM} \mathrm{MgCl}_{2}, 5 \mathrm{mM}$ dithiothreitol (DTT), 10 units of polynucleotide kinase and $10 \mu \mathrm{Ci}$ of $\left[\gamma_{-}{ }^{32} \mathrm{P}\right] \mathrm{ATP}$ at $37{ }^{\circ} \mathrm{C}$ for $30 \mathrm{~min} .1 \mu \mathrm{L}$ of this reaction mixture $(0.05 \mathrm{pmol}$ primer) was added to $0.2 \mathrm{pmol}$ platinated ds-DNA, $400 \mu \mathrm{M}$ dNTP mix and 1 unit Taq DNA polymerase, in a final volume of $10 \mu \mathrm{L}$ buffered with 10 $\mathrm{mM}$ Tris-HCl, $\mathrm{pH} 8.3,1.5 \mathrm{mM} \mathrm{MgCl}_{2}, 50 \mathrm{mM} \mathrm{KCl}$ and $5 \mathrm{mM}$ DTT. Dideoxy sequencing reactions were performed in parallel using the same primers and DNA strand in the absence of platinum. The dNTP mix concentration was reduced to $2.5 \mu \mathrm{M}$ with one of ddT $(1 \mathrm{mM})$, ddA $(500 \mu \mathrm{M})$, ddC $(500 \mu \mathrm{M})$ or ddG $(25 \mu \mathrm{M})$ added as chain terminators. Linear PCR was performed following the cycle $95{ }^{\circ} \mathrm{C}(2 \mathrm{~min}),\left[95{ }^{\circ} \mathrm{C}(1 \mathrm{~min}), 40\right.$ ${ }^{\circ} \mathrm{C}($ Primer 1$) / 60^{\circ} \mathrm{C}$ Primer $2(2 \mathrm{~min})$, and $72{ }^{\circ} \mathrm{C}(2 \mathrm{~min}) \times 10$ ] then $95{ }^{\circ} \mathrm{C}$ for a further 10 minutes before samples were stored on ice. Following amplification samples and dideoxy sequencing reactions $(2 \mu \mathrm{L})$ were mixed with $2 \mu \mathrm{L}$ loading dye (95\% formamide, $0.5 \%$

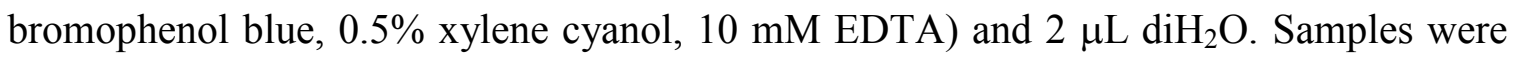
then heated at $95{ }^{\circ} \mathrm{C}$ for 2 mins and cooled on ice before being loaded on a $0.4 \mathrm{~mm}, 8 \%$ polyacrylamide/7M urea sequencing gel, which had been pre-electrophoresed (constant $60 \mathrm{~W}$ ) for 30 minutes. Samples were run for 1 hour and 15 minutes (constant $60 \mathrm{~W}$ ) before being dried on $3 \mathrm{MM}$ paper with a vacuum gel drier $\left(2 \mathrm{~h}\right.$ at $\left.70{ }^{\circ} \mathrm{C}\right)$. The dried gel was then exposed to a phosphor storage screen overnight before being imaged with a phosphorimager. 

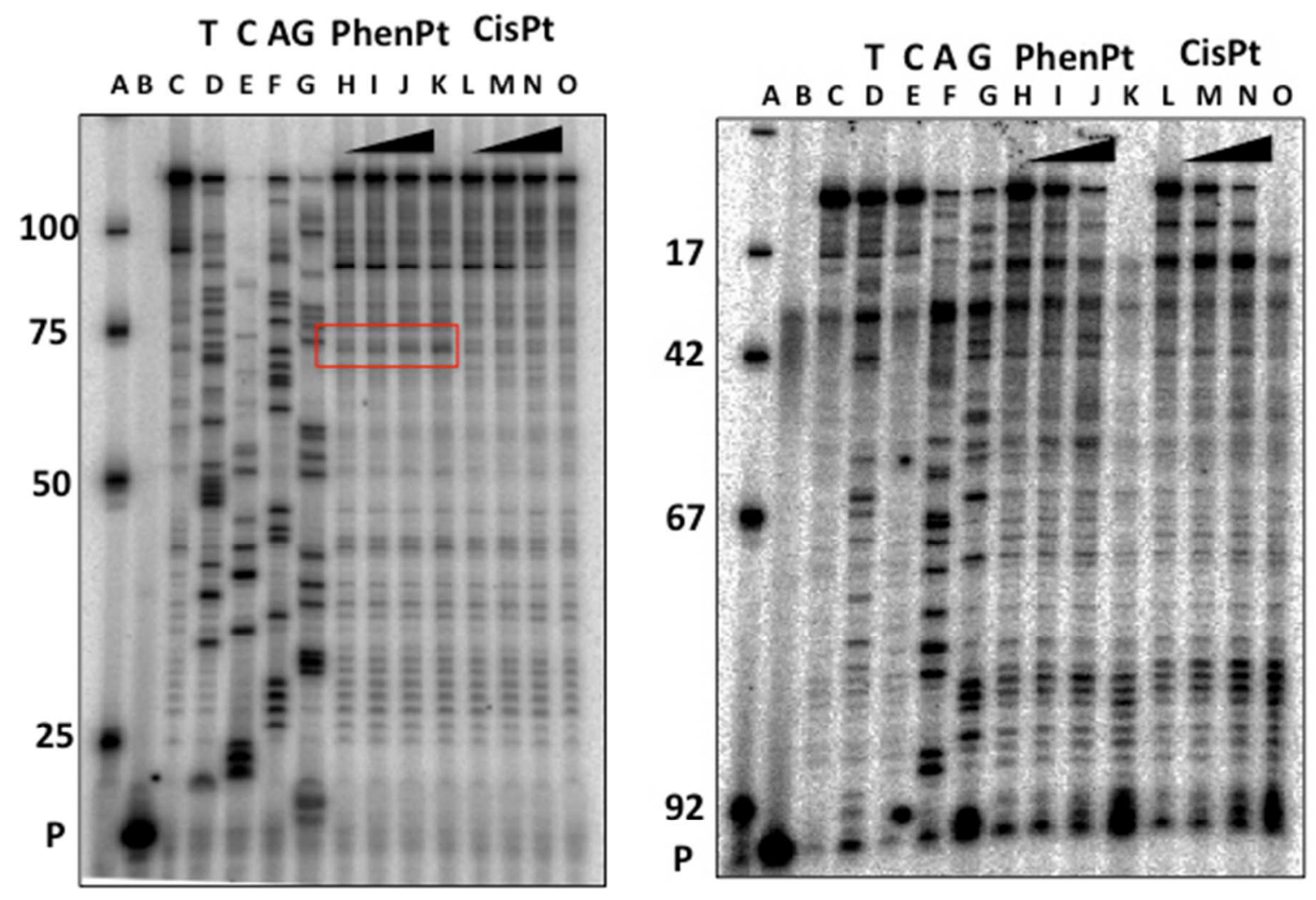

Figure S6: Autoradiographs of replication mapping experiments performed with a 117bp sequence of DNA. Lane A) Low molecular weight ladder; B) unextended primer; C) replication control; D-G) dideoxy sequencing reactions; lanes labeled to correspond to platinated bases, thymine, cytosine, adenine and guanine; H-K) phenanthriplatin $r_{\mathrm{f}}=$ $0.012,0.025,0.05,0.1 ;$ L-O) cisplatin $r_{\mathrm{f}}=0.012,0.025,0.05,0.1$. Left hand image labeled primer 1 (5'-GCGAT TAAGT TGGGT AACG), right hand image labeled primer 2(5'- GACCT CGAGG GGGGG CCGGT AC). Key phenanthriplatin binding site, implicated in Top2 poisoning contained within the red box.

\section{References}

(1) Park, G. Y., Wilson, J. J., Song, Y., and Lippard, S. J. (2012) Phenanthriplatin, a monofunctional DNA-binding platinum anticancer drug candidate with unusual potency and cellular activity profile, Proc. Natl. Acad. Sci. U. S. A. 109, 1198711992. 
(2) Solary, E., Leteurtre, F., Paull, K. D., Scudiero, D., Hamel, E., and Pommier, Y. (1993) Dual inhibition of topoisomerase II and tubulin polymerization by azatoxin, a novel cytotoxic agent, Biochem. Pharmacol. 45, 2449-2456. 